\title{
Prevalence of and risk factors for dynapenic abdominal obesity in community-dwelling older adults: a cross-sectional study
}

\author{
Prevalência e fatores de risco para obesidade abdominal dinapênica \\ em idosos residentes na comunidade: um estudo transversal
}

Fabrícia Coelho de Araújo (https://orcid.org/0000-0002-9748-7569) ${ }^{1}$

Karoline Sampaio da Silva (https://orcid.org/0000-0003-2984-3530) ${ }^{2}$

Daniela Gonçalves Ohara (https://orcid.org/0000-0001-7055-6168) ${ }^{1}$

Areolino Pena Matos (https://orcid.org/0000-0002-3437-5105) ${ }^{1}$

Ana Carolina Pereira Nunes Pinto (https://orcid.org/0000-0002-1505-877X) ${ }^{1}$

Maycon Sousa Pegorari (https:// orcid.org/0000-0003-4015-9895) ${ }^{1}$
${ }^{1}$ Departamento de Ciências Biológicas e da Saúde, Curso de Graduação em Fisioterapia, Universidade Federal do Amapá. Rodovia Juscelino Kubitschek, Jardim Marco Zero. 68903419 Macapá AP Brasil. mayconpegorari@ yahoo.com.br

${ }^{2}$ Curso de Graduação em Enfermagem, Universidade Federal do Amapá. Macapá AP Brasil.

\begin{abstract}
This article aims to identify the prevalence of and factors associated with dynapenic abdominal obesity (DAO) in older adults in a city in the northern region of Brazil. A cross-sectional study was conducted with 382 community-dwelling older adults in Macapa, Amapa, Brazil. Socioeconomic, clinical, and health information were collected using a structured form. DAO was defined as a combination of dynapenia (handgrip strength of $<26 \mathrm{kgf}$ for men and $<16 \mathrm{kgf}$ for women) and abdominal obesity (abdominal circumference $>102 \mathrm{~cm}$ for men and $>88 \mathrm{~cm}$ for women). Descriptive and inferential analyses were performed using chi-squared tests, Student's $t$-tests, and a Poisson regression. The prevalence of DAO was $10.73 \%$. In the preliminary bivariate analysis, the variables of age range, marital status, number of diseases, functional disability for basic and instrumental activities of daily living, gait speed, and level of physical activity met the established criterion. The final model indicated that only gait speed was a predictor of DAO in older adults. DAO affects nearly $11 \%$ of community-dwelling older adults from northern Brazil; gait speed was a predictor of DAO and could be a useful tool for managing and monitoring this population's health.
\end{abstract}

Key words Aged, Health of the elderly, Muscle strength, Obesity, Abdominal, Urban population
Resumo $O$ objetivo deste artigo é identificar a prevalência e os fatores associados à obesidade abdominal dinapênica $(O A D)$ em idosos de uma cidade da região Norte do Brasil. Estudo transversal realizado com 382 idosos comunitários residentes em Macapá, Amapá, Brasil. As informações socioeconômicas, clínicas e de saúde foram coletadas por meio de um formulário estruturado. A OAD foi definida pela combinação de dinapenia (força de preensão manual < $26 \mathrm{kgf}$ para homens $e$ $<16$ kgf para mulheres) e obesidade abdominal (circunferência abdominal $>102 \mathrm{~cm}$ para homens $e>88 \mathrm{~cm}$ para mulheres). As análises descritivas $e$ inferenciais foram realizadas utilizando os testes qui-quadrado, t de Student e regressão de Poisson. A prevalência de $O A D$ foi de $10,73 \%$. Na análise bivariada preliminar, as variáveis faixa etária, estado conjugal, número de doenças, incapacidade funcional para atividades básicas e instrumentais de vida diária, velocidade da marcha e nivel de atividade fisica atenderam ao critério estabelecido. $O$ modelo final indicou que apenas a velocidade da marcha foi um preditor para a OAD em idosos. A OAD afeta quase $11 \%$ dos idosos residentes nessa comunidade do Norte do Brasil; e a velocidade de marcha é um preditor que pode ser uma ferramenta útil para gerenciar e monitorar a saúde desta população.

Palavras-chave Idoso, Saúde do idoso, Força muscular, Obesidade abdominal, População urbana 


\section{Introduction}

The aging process is marked by several physiological changes that lead to the progressive decline of all organic functions ${ }^{1}$. Despite the generalized decline, specific changes - such as those related to body composition - deserve particular study from clinical and public health professionals. Age-related loss of muscle mass is associated with reductions in muscle strength and physical performance ${ }^{2}$ and poor outcomes, such as falls and fractures ${ }^{3}$. However, a reduction in muscle mass alone cannot fully explain losses of muscle strength"; the term "dynapenia" has been recently coined to describe the aging-associated loss of muscle strength as an independent event.

Another salient change in body composition that humans experience during the aging process is the rise in body fat mass. This condition is also associated with a higher risk of comorbidities, disability $^{5}$, and metabolic diseases ${ }^{6}$. However, fat accumulated in the abdominal area is associated with more severe impacts on metabolic disorders than overall obesity ${ }^{7-9}$. Both dynapenia and abdominal obesity are important predictors of poor outcomes, but the confluence of both is a downward spiral that may lead to disability ${ }^{10}$ and multimorbidity ${ }^{11}$. Indeed, dynapenia and abdominal obesity together may better predict functional disability than each phenomenon individually ${ }^{10}$.

Therefore, this recently recognized condition has been termed "dynapenic abdominal obesity" $(\mathrm{DAO})^{10,12}$. DAO represents a severe public health problem, as it is associated with several health burden indicators and healthcare demands. The condition is not only associated with functional disability ${ }^{10}$, but also with an increased risk of falling $^{12}$, hospitalizations $s^{13}$, and death ${ }^{14}$.

Although the consequences of DAO to older adults may be devastating, it has been little investigated. Some studies have examined the association of DAO with specific conditions, such as functional disability ${ }^{10}$, falls $\mathrm{s}^{12}$, hospitalizations ${ }^{13}$, and death ${ }^{14}$. However, to our knowledge, no previous studies have evaluated multiple risk factors - socioeconomic, clinical, and health - and their relationships with the presence of DAO. Furthermore, Brazil is a country with continental dimensions and important socioeconomic, structural, and cultural differences. Despite that, few studies have looked at the elderly population from northern Brazil ${ }^{15,16}$. To address this gap, to identify the prevalence of and factors associated with DAO in older adults in a city in the northern region of Brazil.

\section{Method}

This population-based cross-sectional study was carried out in 2017 in the urban area of Macapa, the capital of the state of Amapa, in Brazil. Macapá is a Brazilian city located on the banks of the Amazon river, in northern Brazil. The city (latitude - 0 2'20» N; longitude - 51 ${ }^{\circ}$ 3' 59» W) is the only Brazilian state that has its capital cut by the imaginary line of the Equator ${ }^{17}$. With a Human Development Index (HDI) of 0.733 and a life expectancy at birth of 74.2 years ${ }^{18}$, Macapá in the year 2010 had an estimated population of 456,171 inhabitants, of which $5.21 \%$ (96\% urban and $4 \%$ rural) were aged 60 years or older ${ }^{19}$. An appropriate sample size was calculated, assuming a prevalence of $50 \%$ of health problems among a finite population of 19,955 older adults living in the urban area of Macapa and setting an accuracy level of $5 \%$ and a $95 \%$ confidence interval (CI). A minimum of 377 individuals was found to be necessary to be representative of the population. To select older adults' residences, the research team carried out a two-stage cluster sampling process by first sampling government-defined pre-specified census tracts and subsequently identifying residences with older people. Select information from this study has been previously analyzed and is available in previously published studies $^{17,20}$.

Adults aged 60 years or over who did not have cognitive decline measured on the Mini-Mental State Examination ${ }^{21}$ and were able to walk with or without walking assistance devices were included. Older adults who were not found after three visits, were institutionalized and/or hospitalized, or affected by neurological diseases that made evaluations impossible were excluded from the study. This study was approved by the Ethics Committee of the Federal University of Amapá (opinion 1,738,671). All the participants agreed to participate in the research by signing an Informed Consent Form. The individuals were recruited and assessed at their respective homes. All interviews were conducted face-to-face by properly trained undergraduate students and monitored by field supervisors (researcher teachers).

\section{Exploratory variables}

A structured questionnaire was used to collect data on all socioeconomic variables: gender, age, education level, physical health variables; referred morbidities, the number of medications in regular use, falls in the past 12 months (yes/ 
no), and hospitalizations in the last year (yes/ no). Self-reported morbidities were surveyed using an inventory ${ }^{22}$ in which participants reported whether any physician had informed if they had certain health condition. Regularly used medications were verified by checking medical prescriptions and by directly asking participants about the medications they were taking. Physical activity levels were evaluated with the long version of the International Physical Activity Questionnaire $(\mathrm{IPAQ})^{23}$. As suggested by the College of Sports Medicine and the American Heart Association, participants who spent 150 minutes or more per week on physical activities were considered sufficiently active; those who spent less than 150 minutes per week on physical activities were classified as insufficiently active ${ }^{24}$. The Katz Index ${ }^{25}$ and the Lawton and Brody Scale ${ }^{26}$ were used to assess functional impairment for basic and instrumental activities of daily living, respectively. Finally, a gait speed test, or measuring the time to walk a four-meter distance, was conducted following the Brazilian version of the Short Physical Performance Battery (SPPB $)^{27}$.

\section{Dependent variable}

Dynapenic abdominal obesity was measured with both muscle strength and abdominal obesity. Muscle strength was measured using a hydraulic hand dynamometer, SAEHAN Hydraulic Hand Dynamometer, model SH5001. The participants were first instructed to sit with their forearm in a neutral position. The device was placed in the participants' dominant hand, and three maximum strength tests were performed with a one-minute rest between tests. The average of these measurements was recorded for analysis. Values below 26 kilogram-force (kgf) for men and below $16 \mathrm{kgf}$ for women were considered suggestive of reduced muscle strength ${ }^{28}$. The second component of DAO, waist circumference, was measured using a non-elastic tape, placed at the midpoint between the last rib and iliac crest, with the abdomen relaxed at the end of exhalation. Standardized measurements were taken with all participants in a standing position, with their arms relaxed at their sides, and clothing removed from the abdominal region ${ }^{29}$. Cut-off points of abdominal circumference $>102 \mathrm{~cm}$ for men and $>88 \mathrm{~cm}$ for women were used to classify abdominal obesity ${ }^{29}$. Participants who fulfilled both the loss of muscle strength and abdominal obesity criteria were considered to have DAO.

\section{Data analysis}

The data were analyzed in version 21.0 of the Statistical Package for Social Sciences (SPSS) program and using both descriptive and inferential statistics. Differences between the participants characteristics were analyzed using means, standard deviations, chi-square tests, and Student's t-tests. The tests were considered significant when $\mathrm{p}<0.20$. The variables that met the pre-established inclusion criterion $(\mathrm{p}<0.20)$ were inserted in the multivariate regression model. The factors associated with DAO were identified from the prevalence ratios (PR) using a Poisson regression, considering a significance level of $5 \%(\mathrm{p}<$ 0.05 ) and $95 \%$ confidence interval (CI).

\section{Results}

Three hundred eighty-two older adults participated in this study. The number of recruited, assessed, included, and excluded participants are outlined in Figure 1. The prevalence of abdominal obesity and dynapenia in the sample was $65.7 \%(n=251)$ and $18.6 \%(n=71)$, respectively, and the prevalence of DAO was $10.73 \%$ $(\mathrm{CI}=08.01-14.24)(\mathrm{n}=41)$. Older people with DAO had a higher age range, number of diseases, without a partner, functional disability for basic activities of daily living, insufficient level of physical activity, and lower gait speed compared to those without DAO (Table 1).

Age range, marital status, number of diseases, functional disability for basic and instrumental activities of daily living, level of physical activity, and gait speed all met the pre-established criterion in the crude analysis $(\mathrm{p}<0.20)$. The final model indicated that only gait speed remained associated with DAO (PR $=0.17$; 95\% CI: 0.05 $0.54 ; p=0.002$ ), suggesting that an increase in one unit of gait speed may decrease the probability of occurrence of this condition by $83 \%$ in older adults (Table 2).

\section{Discussion}

This study in a representative sample of community-dwelling older adults from northern Brazil identified that $\mathrm{DAO}$ is a pervasive condition in this population. To the best of our knowledge, this is the first study to evaluate multiple risk factors associated with the presence of DAO and 


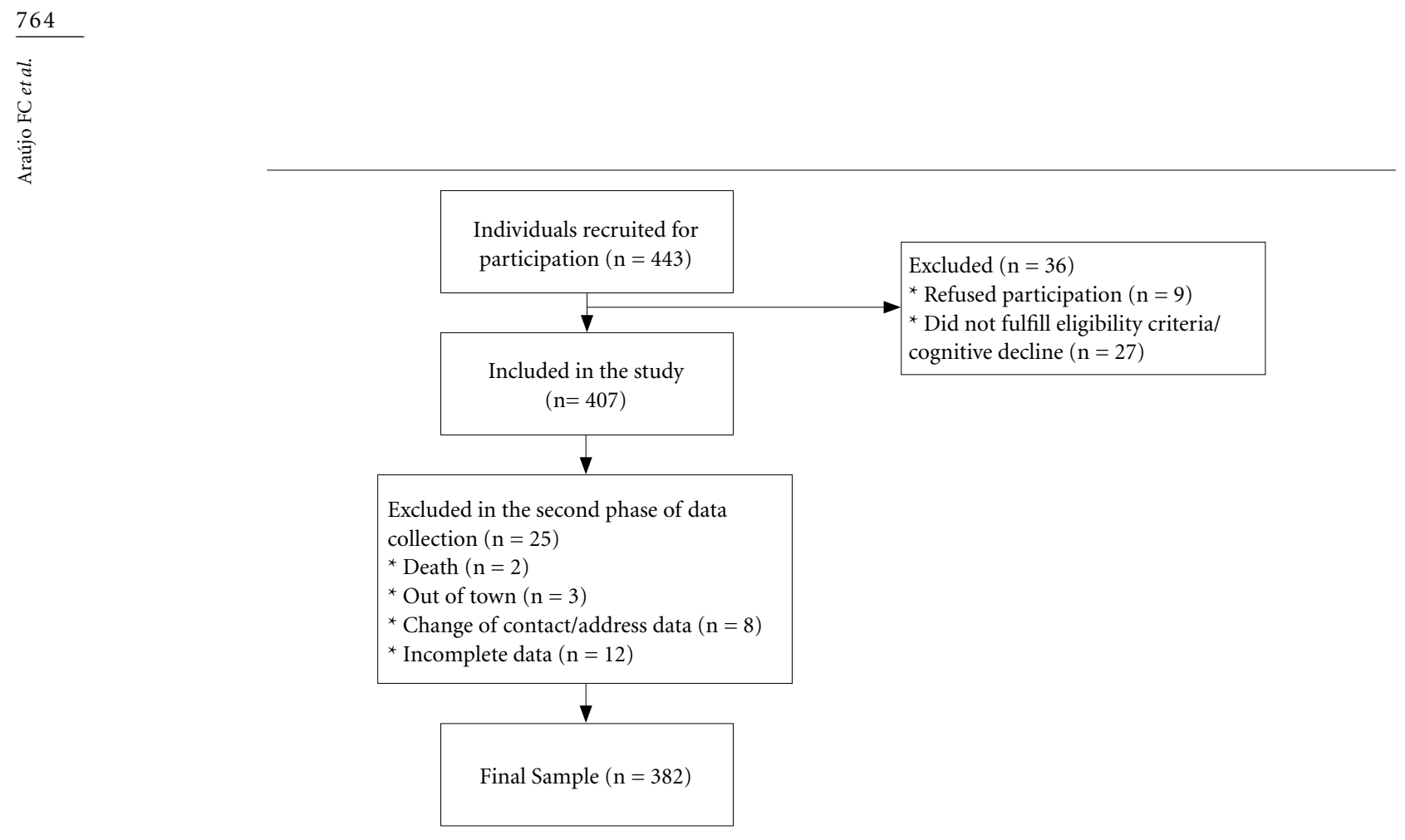

Figure 1. Study flow diagram.

Source: Authors.

provides important insights upon which to base future studies on the subject. The findings presented here may also help formulate strategies for screening patients at higher risk of developing DAO and should be taken into account when designing intervention strategies to preventing the worsening of conditions that could lead to DAO in older adults, such as those focused on improving gait speed. The final model indicated that only gait speed remained a significant predictor of this condition.

In line with a previous study that found a 9.3\% prevalence of DAO in Brazilian older adults $^{12}$, the prevalence of DAO in our sample was $10.7 \%$. Nevertheless, a wide variation in the prevalence of DAO has been found worldwide, with estimations ranging from 4 to $18.8 \% 0^{9,10,12,14}$. The variation in the prevalence may be due to the differences between the studied samples and the population characteristics. A previous study that evaluated older adults from the Amazon region found that these individuals engage in high levels of physical activity ${ }^{15}$. Further studies may clarify the influence of physical activity levels in older adults from the Amazon region and the prevalence of DAO. Additionally, as the concept of DAO is relatively new ${ }^{30}$, no consensus on the diagnostic procedures has been reached yet. There- fore, a possible explanation for this variability in DAO prevalence is that DAO may vary according to the setting and the different studies' operational definition.

The results of our preliminary analysis are also in accordance with previous studies that have found that DAO is associated with age, the number of comorbidities, functional disability for basic and instrumental activities of daily living, level of physical activity, and gait speed ${ }^{13}$. Nevertheless, in our sample, only gait speed remained inversely associated with DAO in the final model.

The reduced gait performance in older people with DAO compared to those without this condition is supported by previous investigations $^{31,32}$. In a cross-sectional study, dynapenic obesity was associated with an increased risk of slow gait speed ${ }^{32}$. Another study highlights that concomitant obesity and low muscle strength may lead not only to a decline in gait speed but also to an increase in the risk of functional disability $^{31}$. Therefore, gait speed limitations can have a substantial impact on autonomy and endurance during activities of daily living. Furthermore, gait speed represents an independent predictor of other adverse health outcomes such as cognitive impairment, institutionalization, falls, and death ${ }^{33}$. 
Table 1. Characteristics of older adults with and without dynapenic abdominal obesity in Macapá, AP, Brazil, $2017(\mathrm{n}=382)$.

\begin{tabular}{|c|c|c|c|c|}
\hline \multirow{2}{*}{ Variables } & \multicolumn{2}{|c|}{ Dynapenic abdominal obesity } & \multirow{2}{*}{ p-value ${ }^{*}$} & \multirow{2}{*}{$\begin{array}{l}\text { Total sample } \\
\quad(\mathbf{n}=\mathbf{3 8 2})\end{array}$} \\
\hline & Yes $(n=41)$ & No $(n=341)$ & & \\
\hline \multicolumn{5}{|l|}{ Age range } \\
\hline 60 to 69 & $14(34.1)$ & $186(54.5)$ & 0.014 & $200(52.4)$ \\
\hline 70 to 79 & $17(41.5)$ & $117(34.3)$ & & $134(35.1)$ \\
\hline 80 or more & $10(24.4)$ & $38(11.1)$ & & $48(12.6)$ \\
\hline \multicolumn{5}{|l|}{ Gender } \\
\hline Male & $11(26.8)$ & $121(35.5)$ & 0.271 & $132(34.6)$ \\
\hline Female & $30(73.2)$ & $220(64.5)$ & & $250(65.4)$ \\
\hline \multicolumn{5}{|l|}{ Marital status } \\
\hline With partner & $11(26.8)$ & $167(49)$ & 0.007 & $178(46.6)$ \\
\hline Without partner & $30(73.2)$ & $174(51)$ & & $204(53.4)$ \\
\hline \multicolumn{5}{|l|}{ Education } \\
\hline None & $20(48.8)$ & $173(50.7)$ & 0.887 & $193(50.5)$ \\
\hline 1 to 4 & $12(29.3)$ & $104(30.5)$ & & $116(30.4)$ \\
\hline 5 or more & $9(22)$ & $64(18.8)$ & & $73(19.1)$ \\
\hline \multicolumn{5}{|l|}{ Individual monthly income } \\
\hline No income & $3(7.3)$ & $33(9.7)$ & 0.377 & $36(9.4)$ \\
\hline Up to 1 minimum wage & $25(61)$ & $159(46.6)$ & & $184(48.2)$ \\
\hline 2 to 3 minimum wages & $8(19.5)$ & $98(28.7)$ & & $106(27.7)$ \\
\hline 4 or more minimum wages & $5(12.2)$ & $51(15)$ & & $56(14.7)$ \\
\hline \multicolumn{5}{|l|}{ Number of diseases } \\
\hline 0 & $0(0)$ & $28(8.2)$ & 0.163 & $28(7.3)$ \\
\hline 1 to 4 & $15(36.6)$ & $115(33.7)$ & & $130(34)$ \\
\hline 5 or more & $26(63.4)$ & $198(58.1)$ & & $224(58.6)$ \\
\hline \multicolumn{5}{|l|}{ Number of medications } \\
\hline 0 & $11(26.8)$ & $112(32.8)$ & 0.679 & $123(32.2)$ \\
\hline 1 to 4 & $26(63.4)$ & $204(59.8)$ & & $230(60.2)$ \\
\hline 5 or more & $4(9.80$ & $25(7.3)$ & & $29(7.6)$ \\
\hline \multicolumn{5}{|l|}{ Smoking } \\
\hline Yes & $3(7.3)$ & $33(9.7)$ & 0.837 & $36(9.4)$ \\
\hline No & $38(92.7)$ & $308(90.3)$ & & $346(90.6)$ \\
\hline \multicolumn{5}{|l|}{ Hospitalization in the least year } \\
\hline Yes & $7(17.10)$ & $44(12.90)$ & 0.458 & $51(13.40)$ \\
\hline No & $34(82.90)$ & $297(87.10)$ & & $331(86.60)$ \\
\hline \multicolumn{5}{|l|}{ Falls in the past 12 months } \\
\hline Yes & $9(22.00)$ & $66(19.40)$ & 0.693 & $75(19.60)$ \\
\hline No & $32(78.00)$ & $275(87.10)$ & & $307(80.41)$ \\
\hline Walking speed $(\mathrm{m} / \mathrm{s})$ & $0.78 \pm 0.27$ & $1.02 \pm 0.30$ & $<0.001$ & $(0.99 \pm 0.30)$ \\
\hline \multicolumn{5}{|l|}{ Physical activity (IPAQ) ${ }^{\dagger}$} \\
\hline Insufficiently active ( $\leq 149 \mathrm{~min} . /$ week $)$ & $14(34.10)$ & $191(56.00)$ & 0.008 & $205(53.70)$ \\
\hline Sufficiently active ( $\geq 150 \mathrm{~min} . /$ week $)$ & $27(65.90)$ & $150(44.00)$ & & $177(46.30)$ \\
\hline \multicolumn{5}{|l|}{ Dependence (Katz index) } \\
\hline Yes & $6(14.60)$ & $17(5.00)$ & 0.014 & $23(6.00)$ \\
\hline No & $35(84.40)$ & $324(95.00)$ & & $359(94.00)$ \\
\hline \multicolumn{5}{|l|}{ Dependence (Lawton and Brody scale) } \\
\hline Yes & $33(80.50)$ & $230(64.70)$ & 0.089 & $263(68.80)$ \\
\hline No & $8(19.50)$ & $111(32.60)$ & & $119(31.20)$ \\
\hline
\end{tabular}

Source: Authors. 
Table 2. Poisson regression model for factors associated with dynapenic abdominal obesity among communitydwelling older adults in Macapá, AP, Brazil, 2017 ( $\mathrm{n}=382)$.

\begin{tabular}{|c|c|c|c|c|c|c|}
\hline \multirow{2}{*}{ Variables } & \multicolumn{6}{|c|}{ Dynapenic abdominal obesity } \\
\hline & $\mathbf{P R}_{\text {crude }}^{*}$ & $95 \% \mathrm{CI}^{\dagger}$ & p-value ${ }^{\dagger \dagger}$ & PR adjusted $^{\ddagger}$ & $95 \% \mathrm{CI}$ & p-value \\
\hline \multicolumn{7}{|l|}{ Age range } \\
\hline 60 to 69 & & 1 & & & 1 & \\
\hline 70 to 79 & 1.81 & $0.92-3.55$ & 0.083 & 1.41 & $0.68-2.92$ & 0.352 \\
\hline 80 or more & 2.98 & $1.41-6.29$ & 0.004 & 1.48 & $0.60-3.48$ & 0.409 \\
\hline \multicolumn{7}{|l|}{ Gender } \\
\hline Male & & 1 & & & & \\
\hline Female & 1.44 & $0.75-2.87$ & 0.277 & & & \\
\hline \multicolumn{7}{|l|}{ Marital status } \\
\hline With partner & 2.38 & $1.23-4.61$ & 0.010 & 1.63 & $0.79-3.35$ & 0.184 \\
\hline Without partner & & 1 & & & 1 & \\
\hline \multicolumn{7}{|l|}{ Education (years) } \\
\hline None & 1.19 & $0.57-2.49$ & 0.645 & & & \\
\hline 1 to 4 & 0.99 & $0.51-1.97$ & 0.996 & & & \\
\hline 5 or more & & 1 & & & & \\
\hline \multicolumn{7}{|l|}{ Individual monthly income } \\
\hline No income & 0.93 & $0.22-3.90$ & 0.925 & & & \\
\hline Up to 1 minimum wage & 1.52 & $0.58-3.97$ & 0.391 & & & \\
\hline 2 to 3 minimum wages & 084 & $0.27-2.58$ & 0.768 & & & \\
\hline 4 or more minimum wage & & 1 & & & & \\
\hline Number of diseases & 1.09 & $0.99-1.21$ & 0.077 & 0.99 & $0.89-1.11$ & 0.887 \\
\hline \multicolumn{7}{|l|}{ Number of medications } \\
\hline 0 & & 1 & & & & \\
\hline 1 to 4 & 0.82 & $0.31-2.18$ & 0.690 & & & \\
\hline 5 or more & 0.65 & $0.22-1.91$ & 0.436 & & & \\
\hline \multicolumn{7}{|l|}{ Smoking } \\
\hline Yes & 0.76 & $0.25-2.33$ & 0.630 & & & \\
\hline No & & 1 & & & & \\
\hline \multicolumn{7}{|l|}{ Hospitalizations in the last year } \\
\hline Yes & 1.34 & $0.63-2.85$ & 0.454 & & & \\
\hline No & & 1 & & & & \\
\hline \multicolumn{7}{|l|}{ Falls in the past 12 months } \\
\hline Yes & 1.15 & $0.57-2.31$ & 0.691 & & & \\
\hline No & & 1 & & & & \\
\hline \multicolumn{7}{|l|}{ Functional disability (BADLs) ${ }^{\S}$} \\
\hline Yes & 2.68 & $1.26-5.70$ & 0.011 & 1.71 & $0.65-4.49$ & 0.272 \\
\hline No & & 1 & & & 1 & \\
\hline \multicolumn{7}{|l|}{ Functional disability (IADLs) ${ }^{\prime}$} \\
\hline Yes & 1.87 & $0.89-3.91$ & 0.088 & 0.95 & $0.40-2.24$ & 0.911 \\
\hline No & & 1 & & & 1 & \\
\hline \multicolumn{7}{|l|}{ Physical activity level (IPAQ) } \\
\hline Sufficiently active ( $\geq 150 \mathrm{~min} . / \mathrm{sem})$. & & 1 & & & 1 & \\
\hline Insufficiently active ( $\leq 149 \mathrm{~min} . / \mathrm{sem})$. & 2.23 & $1.21-4.12$ & 0.010 & 1.35 & $0.66-2.74$ & 0.413 \\
\hline Gait speed $(\mathrm{m} / \mathrm{s})$ & 0.11 & $0.04-0.28$ & $<0.001$ & 0.17 & $0.05-0.54$ & 0.002 \\
\hline
\end{tabular}

${ }^{\mathrm{PRR}}=$ prevalence ratios; ${ }^{\dagger} \mathrm{CI}=95 \%$ confidence interval; ${ }^{\dagger \dagger} \mathrm{p}<020 ;{ }^{\ddagger} \mathrm{p}<005 ;{ }^{\varsigma} \mathrm{BADL} s=$ basic activities of daily living; ${ }^{\prime}$ IADLs $=$ instrumental activities of daily living; 'IPAQ = International Physical Activity Questionnaire.

Source: Authors. 
Of note, reduced leg strength ${ }^{34}$ and a high fat mass ${ }^{35}$ are modifiable risk factors that, if not early managed, can lead to potentially-disabling conditions and a potentialized burden in older adults' lives. Targeted health care interventions such as exercise and nutrition may help prevent unfavorable health outcomes in this population.

Taken together, our findings reinforce the relevance of the gait speed assessment as a useful tool for managing and monitoring this population's health. Importantly, the cross-sectional design of this study does not allow us to ascertain a causal relationship between DAO and slow gait speed. Further longitudinal studies may help clarify the temporal sequence of those events. Additionally, although the IPAQ was developed for international use and has evidence of reliability and validity ${ }^{36}$, as it is a self-reported instrument some older adults older adults may not fully comprehend the amount of time they may spend active, sitting and/or lying during waking hours, especially those with lower educational level. On the other hand, this study made up of a representative sample of community-dwelling older adults the final model indicated that gait speed is a central element to be considered while evaluating older adults with DAO. It is a simple, non-invasive, low-cost, and easy-to-perform assessment that can help identify older adults at higher risk of adverse health outcomes ${ }^{33}$, help implement effective interventions, and prevent further deterioration in quality of life.

\section{Conclusion}

DAO affects nearly $11 \%$ of community-dwelling older adults from northern Brazil. The final model revealed that only gait speed remained associated with DAO, indicating that a 1 unit increase in gait speed may decrease the likelihood of occurrence of DAO by $83 \%$ in older adults. Gait speed could be a useful tool for managing and monitoring this population's health.

\section{Collaborations}

All the authors contributed to the conception and design, analysis and interpretation of the research data, as well as to the writing and critical review of the article. All authors read and approved the final version of the manuscript for publication. 


\section{References}

1. Khan S, Singer B, Vaughan D. Molecular and physiological manifestations and measurement of aging in humans. Aging cell 2017; 16(4):624-633.

2. Baumgartner RN. Body composition in healthy aging. Ann N Y Acad Sci 2000; 904:437-448.

3. Yeung SSY, Reijnierse EM, Pham VK, Trappenburg MC, Lim WK, Meskers CGM, Maier AB. Sarcopenia and its association with falls and fractures in older adults: a systematic review and meta-analysis. Journal of cachexia, sarcopenia and muscle 2019; 10(3):485500.

4. Clark BC, Manini TM. Sarcopenia $=/=$ dynapenia. $J$ Gerontol A Biol Sci Med Sci 2008; 63(8):829-834.

5. Vincent HK, Vincent KR, Lamb KM. Obesity and mobility disability in the older adult. Obes Rev 2010; 11(8):568-579.

6. Polotsky HN, Polotsky AJ. Metabolic implications of menopause. Semin Reprod Med 2010; 28(5):426-434.

7. Janssen I, Katzmarzyk PT, Ross R. Waist circumference and not body mass index explains obesity-related health risk. The American Journal of Clinical Nutrition 2004; 79(3):379-384.

8. Koster A, Leitzmann MF, Schatzkin A, Mouw T, Adams KF, van Eijk JT, Hollenbeck AR, Harris TB. Waist circumference and mortality. Am J Epidemiol 2008; 167(12):1465-1475.

9. Senechal M, Dionne IJ, Brochu M. Dynapenic abdominal obesity and metabolic risk factors in adults 50 years of age and older. J Aging Health 2012; 24(5):812826.

10. Alexandre TDS, Scholes S, Santos JLF, Oliveira C. Dynapenic abdominal obesity as a risk factor for worse trajectories of ADL disability among older adults: the ELSA Cohort Study. J Gerontol A Biol Sci Med Sci 2019; 74(7):1112-1118.

11. Montes M, Bortolotto C, Tomasi E, Gonzalez MC, Barbosa-Silva T, Domingues M, Bielemann R. Grip strength and multimorbidity among communitydwelling elderly from Southern Brazil. Nutrition 2019; 71:110636.

12. Máximo RO, Santos JLF, Perracini MR, Oliveira C, Duarte YAO, Alexandre TDS. Abdominal obesity, dynapenia and dynapenic-abdominal obesity as factors associated with falls. Braz J Phys Ther 2019; 23(6):497505.

13. Rossi AP, Bianchi L, Volpato S, Bandinelli S, Guralnik J, Zamboni M, Ferrucci L. Dynapenic abdominal obesity as a predictor of worsening disability, hospitalization, and mortality in older adults: results from the InCHIANTI Study. J Gerontol A Biol Sci Med Sci 2017; 72(8):1098-1104.

14. Alexandre T, Scholes S, Ferreira Santos JL, Duarte Y, Oliveira C. Dynapenic abdominal obesity increases mortality risk among english and brazilian older adults: a 10-year follow-up of the ELSA and SABE studies. J Nutr Health Aging 2017; 22:1-7.
15. Freire Junior RC, Fernandes TG, Borges GF, Guerra RO, Abreu DCC. Factors associated with low levels of physical activity among elderly residents in a small urban area in the interior of the Brazilian Amazon. Arch Gerontol Geriatr 2018; 75:37-43.

16. Esteves CL, Ohara DG, Matos AP, Ferreira VTK, Iosimuta NCR, Pegorari MS. Anthropometric indicators as a discriminator of sarcopenia in community-dwelling older adults of the Amazon region: a cross-sectional study. BMC Geriatr 2020; 20(1):518.

17. Ohara DG, Pegorari MS, Santos NLO, Silva CFR, Monteiro RL, Matos AP, Jamami M. Respiratory muscle strength as a discriminator of sarcopenia in community-dwelling elderly: a cross-sectional Study. J Nutr Health Aging 2018; 22(8):952-958.

18. Instituto Brasileiro de Geografia e Estatística (IBGE). Cidades. Macapá 2010 [Internet]. [cited 2020 Ago 5]. Available from: http://www.cidades.ibge.gov.br

19. Instituto Brasileiro de Geografia e Estatística [IBGE]. Síntese de Indicadores Sociais: uma análise das condições de vida da população brasileira 2010 [Internet]. [cited 2020 Ago 5]. Available from: https://biblioteca. ibge.gov.br/visualizacao/livros/liv45700.pdf

20. Ohara DG, Pegorari MS, Santos NLO, d Silva CFR, Oliveira MSR, Matos AP, Jamami M. Cross-Sectional Study on the association between pulmonary function and sarcopenia in Brazilian community-dwelling elderly from the Amazon Region. J Nutr Health Aging 2020; 24(2):181-187.

21. Bertolucci PH, Brucki SM, Campacci SR, Juliano Y. The Mini-Mental State Examination in a general population: impact of educational status. Arq Neuropsiquiatr 1994; 52(1):1-7.

22. Tavares D, Pelizaro PB, Pegorari MS, Paiva MM, Marchiori GF. Prevalence of self-reported morbidities and associated factors among community-dwelling elderly in Uberaba, Minas Gerais, Brazil. Cien Saude Colet 2019; 24(9):3305-3313.

23. Benedetti TB, Mazo GZ, de Barros MVG. Application of the International Physical Activity Questionnaire (IPAQ) for evaluation of elderly women: concurrent validity and test-retest reprodutibility. $\mathrm{R}$ Bras $\mathrm{Ci}$ e Mov 2004; 12(1):25-34.

24. Pate RR, Pratt M, Blair SN, Haskell WL, Macera CA, Bouchard C, Buchner D, Ettinger W, Heath GW, King AC, Kriska A, Leon AS, Marcus BH, Morris J, Paffenbarger Jr RS, Patrick K, Pollock ML, Rippe JM, Sallis J, Wilmore JH. Physical Activity and Public Health. A recommendation from the centers for disease control and prevention and the American College of Sports Medicine. JAMA 1995; 273(5):402-407.

25. Lino VPS, Camacho L, Ribeiro Filho S, Buksman S. Cross-cultural adaptation of the Independence in Activities of Daily Living Index (Katz Index). Cad Saude Publica 2008; 24(1):102-112.

26. Santos R, Virtuoso Junior J. Reliability of the Brazilian version of the Scale of Instrumental Activities of Daily Living. RBPS 2008; 21(4):290-296. 
27. Nakano MM. Brazilian version of the Short Physical Performance Battery - SPPB: cross-cultural adaptation and reliability study. Sao Paulo: Faculdade de Educação, Universidade Estadual de Campinas; 2007.

28. Alley DE, Shardell MD, Peters KW, McLean RR, Dam TT, Kenny AM, Fragala MS, Harris TB, Kiel DP, Guralnik JM, Ferrucci L, Kritchevsky SB, Studenski SA, Vassileva MT, Cawthon PM. Grip strength cutpoints for the identification of clinically relevant weakness. $J$ Gerontol A Biol Sci Med Sci 2014; 69(5):559-566.

29. National Institute of Health. The Practical Guide. Identification, Evaluation, and Treatment of Overweight and Obesity in Adults 2000 [Internet]. [cited 2020 Ago 5]. Available from: https://www.nhlbi.nih.gov/ files/docs/guidelines/prctgd_c.pdf

30. Rossi AP, Fantin F, Caliari C, Zoico E, Mazzali G, Zanardo M, Bertassello P, Zanandrea V, Micciolo R, Zamboni M. Dynapenic abdominal obesity as predictor of mortality and disability worsening in older adults: a 10-year prospective study. Clin Nutr 2016; 35(1):199-204.

31. Stenholm S, Alley D, Bandinelli S, Griswold ME, Koskinen S, Rantanen T, Guralnik JM, Ferrucci L. The effect of obesity combined with low muscle strength on decline in mobility in older persons: results from the InCHIANTI study. Int J Obes (Lond) 2009; 33(6):635-644.

32. Bouchard DR, Janssen I. Dynapenic-obesity and physical function in older adults. J Gerontol A Biol Sci Med Sci 2010; 65(1):71-77.

33. Abellan van Kan G, Rolland Y, Andrieu S, Bauer J, Beauchet O, Bonnefoy M, Cesari M, Donini LM, Gillette Guyonnet S, Inzitari M, Nourhashemi F, Onder G, Ritz P, Salva A, Visser M, Vellas B. Gait speed at usual pace as a predictor of adverse outcomes in community-dwelling older people an International Academy on Nutrition and Aging (IANA) Task Force. J Nutr Health Aging 2009; 13(10):881-889.

34. Latham NK, Bennett DA, Stretton CM, Anderson CS. Systematic review of progressive resistance strength training in older adults. J Gerontol A Biol Sci Med Sci 2004; 59(1):48-61.

35. Villareal DT, Banks M, Sinacore DR, Siener C, Klein S. Effect of Weight Loss and Exercise on Frailty in Obese Older Adults. Archives of Internal Medicine 2006; 166(8):860-866.

36. Craig CL, Marshall AL, Sjöström M, Bauman AE, Booth ML, Ainsworth BE, Pratt M, Ekelund U, Yngve A, Sallis JF, Oja P. International physical activity questionnaire: 12 -country reliability and validity. Med Sci Sports Exerc 2003; 35(8):1381-1395.

Article submitted 16/09/2020

Approved 02/02/2021

Final version submitted 04/02/2021

Chief editors: Romeu Gomes, Antônio Augusto Moura da Silva 
